M

етилпреднизолона ацепонат и декспантенол в топической терапии больных атопическим дерматитом

\title{
В.В. Чикин
}

ФГБУ «Государственный научный центр дерматовенерологии и косметологии» Минздрава России 107076, Москва, ул. Короленко, д. 3, стр. 6

Целями топической терапии больных атопическим дерматитом являются подавление воспалительной реакции в коже, устранение зуда, восстановление разрушенного защитного липидного барьера эпидермиса. В связи с этим в терапии больных атопическим дерматитом используются топические глюкокортикостероиды и средства, увлажняющие кожу. Высокой эфффективностью и безопасностью характеризуется топический глюкокортикостероид метилпреднизолна ацепонат (МПА, Адвантан). Для МПА характерно быстрое развитие терапевтического эффеекта. Препарат может применяться у детей, начиная с возраста 4 месяца, его можно использовать 1 раз в сутки. Наличие у МПА 4 лекарственных фрорм (эмульсия, крем, мазь и жирная мазь) позволяет выбирать терапию этим препаратом с учетом стадии и локализации поражения кожи. Стимулятор репарации тканей декспантенол (Бепантен) увлажняет кожу, защищает ее от воздействия раздражителей, восстанавливает защитный липидный барьер эпидермиса. Использование комбинации топического глюкокортикостероида МПА и стимулятора репарации тканей декспантенола может повысить эсроективность терапии больных атопическим дерматитом.

Ключевые слова: атопический дерматит, топическая терапия, метилпреднизолона ацепонат, декспантенол.

Контактная инсрормация: сnikin@cnikvi.ru. Вестник дерматологии и венерологии 2014; (5): 112_116.

\section{T opical methylprednisolone aceponate and dexpanthenol in the treatment of patients with atopic dermatitis}

V.V. Chikin

State Research Center of Dermatovenereology and Cosmetology, Ministry of Healthcare of the Russian Federation Korolenko str., 3, bldg 6, Moscow, 107076, Russia

The goals of the topical treatment of patients suffering from atopic dermatitis are suppression of the inflammatory reaction in the skin, elimination of itching, and recovery of the damaged protective lipid barrier of the epidermis. In this connection, topical glucocorticosteroids and skin moisturizers are used in the therapy of patients suffering from atopic dermatitis. Methylprednisolone aceponate (MPA, Advantan) being a topical glucocorticosteroid is characterized by high efficacy and safety. MPA is marked by the fast development of the therapeutic effect.

This drug can be used for children older than 4 months and can be applied once a day.

The availability of four dosage forms of MPA (emulsion, cream, ointment and fatty ointment) enables physicians to select a therapy with the use of this drug depending on the stage and localization of the skin lesion. Dexpanthenol (Bepanthen) being a tissue repair stimulator moisturizes the skin, protects the skin against an irritant effect, and restores the protective lipid barrier of the epidermis. The use of a combination of MPA being a topical glucocorticosteroid and dexpanthenol being a tissue repair stimulator can enhance the efficacy of the treatment of patients suffering from atopic dermatitis.

Key words: atopic dermatitis, topical treatment, methylprednisolone aceponate, dexpanthenol. 
Атопический дерматит является одним из наиболее распространенных хронических воспалительных заболеваний кожи, характеризующимся высокой заболеваемостью в детском возрасте и постепенным улучшением состояния больных с возрастом. Оценивается, что атопическим дерматитом страдают 10-20\% детей и до 3\% взрослых [1-3]. Распространенность заболевания максимальна среди пациентов в возрасте первых двух лет жизни [4].

С наличием высыпаний, которые сопровождаются характерным для атопического дерматита зудом, с потребностью в проведении терапевтических мероприятий, требующих существенных фринансовых затрат и затрат времени, связано значительное снижение качества жизни больных атопическим дерматитом, у которых могут отмечаться тревожность, депрессия, бессонница [5-7].

В основе патогенеза атопического дерматита лежат нарушения иммунных реакций, характеризующиеся продукцией Th2-лимфроцитами соответствующих цитокинов - интерлейкинов-4, $-5,-13$ с развитием воспалительной реакции в коже и зуда, и повреждение защитного липидного барьера эпидермиса, что облегчает проникновение веществ из окружающей среды через кожу и клинически проявляется ее сухостью. В связи с этим патогенетическая терапия больных атопическим дерматитом направлена в первую очередь на подавление воспалительной реакции в коже, восстановление защитного липидного барьера эпидермиса, устранение зуда.

Основой лечения больных атопическим дерматитом называют наружную терапию [8], которая показана каждому пациенту независимо от степени тяжести заболевания. Если для восстановления защитного барьера и устранения сухости кожи больным атопическим дерматитом рекомендуют использование эмолиентов, то в основе противовоспалительной терапии при этом заболевании лежат топические глюкокортикостероиды [8].

Известны требования, предъявляемые к топическим глюкокортикостероидам. Это быстрое развитие противовоспалительного эффекта, разнообразие лекарственных форм для возможности получения оптимального эффекта на любой стадии воспалительного процесса на любом участке кожи, удобство применения (использование 1 раз в сутки, хорошие косметические свойства), безопасность (низкая всасываемость с поверхности кожи и полная быстрая инактивация в крови, минимум побочных эфрфектов), возможность использования в любом возрасте даже при длительном применении, наличие достоверных данных, подтверждающих особенности препаратов в соответствии со стандартами доказательной медицины [9]. В случае атопического дерматита имеет значение возраст, в котором можно использовать топический глюкокортикостероидный препарат, поскольку большинство больных атопическим дерматитом - дети. Всем этим требованиям отвечает метилпреднизолона ацепонат (МПА, Адвантан).

МПА является негалогенизированным диэфирным глюкокортикостероидом. Наличие двух эфирных групп в положениях C17 и С21 (двойная эстерификация) придает молекуле МПА высоколипофильные свойства, что позволяет ей быстро проникать в роговой слой. Благодаря своей липофильности МПА после нанесения на кожные покровы остается в коже, за счет чего создается высокая концентрация препарата в месте аппликации.

После абсорбции в кожу МПА гидролизуется эстеразами с образованием его активного метаболита метилпреднизолона 17-пропионата (МПП), который проявляет большую аффинность к кортикостероидному рецептору, чем его родительское соединение МПА. В воспаленной коже биоактивация МПА ускоряется из-за относительно более высокого уровня эстераз в очаге воспаления.

С липофильностью молекулы МПА связано то, что лишь незначительное количество этого вещества проникает из кожи в кровь. Поэтому концентрация МПА в сыворотке крови не достигает высоких значений, тем самым снижается вероятность развития системных нежелательных являений. МПП после системной абсорбции быстро инактивируется путем конъюгации с глюкуроновой кислотой с образованием неактивного глюкуронида МПП, который выделяется главным образом с мочой, что также уменьшает риск развития системных нежелательных явлений.

По классификации Миллера - Монро МПА (Адвантан) относится к активным кортикостероидам (III класс активности - сильные). Он может применяться у детей начиная с 4-месячного возраста. Выпускается Адвантан в 4 различных лекарственных формах (эмульсия, крем, мазь, жирная мазь).

Выбор лекарственной формы топического глюкокортикостероида определяется стадией, локализацией очагов поражения и степенью тяжести заболевания кожи. При экссудации и мокнутии предпочтение отдается лекарственным формам с более высоким содержанием воды, в сухих инфильтрированных очагах поражения кожи предпочтительны лекарственные формы с более высоким содержанием жира. Основа топического лекарственного средства влияет также на глубину проникновения действующего вещества, которая увеличивается по мере увеличения содержания жиров в топическом препарате.

Все лекарственные формы Адвантана содержат 1 мг МПА в 1 г препарата (0,1\%), однако различаются по содержанию воды. Эмульсия Адвантан отличается наиболее высоким содержанием воды (67,55\%) среди всех лекарственных фрорм топического препарата Адвантан. Она может применяться для лечения поражений кожи, сопровождающихся экссудацией 
и мокнутием, при локализации высыпаний на чувствительных к действию глюкокортикостероидов участках кожного покрова - на лице, в складках кожи, а также на волосистой части головы. Крем Адвантан содержит $60 \%$ воды и показан для лечения острых воспалительных поражений кожи, которые проявляются эритемой и отеком, но не сопровождаются мокнутием. Крем Адвантан может наноситься на любой участок тела, включая лицо, он хорошо впитывается и смягчает кожу. В состав мази Адвантан входит 30\% воды. За счет более высокого по сравнению с эмульсией и кремом содержания жирная мазь слегка ожиряет кожу, однако она не препятствует теплообмену и выделению воды. Ее применение показано при подостром и хроническом воспалительном процессе при отсутствии мокнутия, когда заболевание кожи проявляется очагами воспалительной инфильтрации, при наличии очагов гиперкератоза, трещин, сухости кожи. Жирная мазь Адвантан является безводной, что позволяет ей обеспечивать окклюзионный эффрект и препятствовать испарению воды с поверхности кожи. Жирная мазь эфффективна при назначении подросткам и взрослым больным с длительно существующими очагами инфильтрации и лихенификации.

Клинические исследования эффрективности и безопасности МПА подтвердили соответствие выпускаемого в различных лекарственных формах препарата Адвантан (эмульсия, крем, мазь, жирная мазь) требованиям, предъявляемым к топическим глюкокортикостероидам.

Способность МПА задерживаться и накапливаться в коже позволяет использовать препарат 1 раз в сутки. При изучении эфрфективности МПА, назначавшегося больным атопическим дерматитом 1 или 2 раза в день, было выявлено, что кратность аппликаций препарата не влияет на эфффективность терапии [10].

При нанесении на кожу МПА характеризуется быстрым развитием терапевтического эффекта. Отмечается, что у 65\% детей, больных атопическим дерматитом, уже через 2-3 дня наружной терапии 0,1\% МПА значительно уменьшилась выраженность клинических проявлений заболевания, особенно эритемы и зуда [11]. Раннее эффрективное прекращение зуда особенно важно для пациентов детского возраста, которым трудно отказаться от расчесывания. Использование МПА позволяет значительно уменьшить выраженность не только объективных признаков заболевания кожи (эритемы, везикуляции, мокнутия, образования корок, шелушения и лихенификации), но и субъективных проявлений болезни (зуд, чувство жжения) и приводит к значительному улучшению состояния пациентов или полной ремиссии больных [12].

Показано, что по своей эффрективности наружная терапия больных атопическим дерматитом 0,1\% жирной мазью МПА не уступала мази бетаметазона валерата. Лечение 0,1\% жирной мазью МПА привело к зна- чительному улучшению у $27 \%$ больных атопическим дерматитом и к полной ремиссии - у 66\% больных (общий уровень ответа на лечение - 93\%), тогда как использование мази бетаметазона валерата привело к значительному улучшению у $30 \%$ больных атопическим дерматитом, а у 68\% пациентов была достигнута полная ремиссия (общий уровень ответа - 98\%) [10]. В клиническом исследовании с участием 265 детей, больных тяжелым атопическим дерматитом, было показано, что по терапевтической эфффективности 0,1\% мазь МПА, которую наносили на очаги поражения кожи 1 раз в день, сопоставима 0,03\% мази такролимуca, аппликации которой проводили 2 раза в день [13].

Хотя МПА является топическим глюкокортикостероидом высокой степени активности, развитие локальных и системных нежелательных явлений при его использовании нехарактерно. В исследованиях с участием здоровых добровольцев была показана низкая абсорбция МПА как в здоровую кожу, так и в кожу, в которой с помощью ультрафиолетового облучения была индуцирована воспалительная реакция [14]. Указывается, что нанесение крема МПА на кожу здоровых лиц 1 раз в день не приводило к значительному уменьшению толщины кожи [15]. Не влияло на толщину кожи и не вызывало развитие атрофии кожи проведение аппликаций МПА на кожу предплечья здоровых добровольцев в течение 3 недель под окклюзию [16].

При использовании жирной мази МПА для лечения больных атопическим дерматитом локальные нежелательные явления, самым частым из которых были фолликулиты, выявлены только у 4,3\% пациентов, а признаки атрофии кожи и телеангиэктазии не определялись. Лишь у 1,1\% больных атопическим дерматитом терапия жирной мазью МПА была прервана изза развития нежелательных явлений [10]. Приводятся данные о минимальном эффректе МПА на гипоталамогипофизарно-надпочечниковую ось и уровень кортизола в плазме крови даже при длительном, в течение 4-6 месяцев, применении препарата [15].

Высокую эффективность и безопасность МПА отражает его терапевтический индекс - соотношение между объективными параметрами эффективности препарата и его нежелательными эффректами. Когда эффективность препарата преобладает над его нежелательными эффектами, его терапевтический индекс составляет больше 2. У МПА один из наиболее высоких для топических кортикостероидов терапевтический индекс - 2,0.

Улучшить результаты терапии больных атопическим дерматитом топическими глюкокортикостероидами может одновременное применение эмолиентов [17]. Было показано, что использование эмолиентов в лечении детей, больных атопическим дерматитом, вместе с топическим глюкокортикостероидом МПА привело к значительному уменьшению сухости 
кожи и зуда и способствовало сохранению достигнутой у пациентов ремиссии [18].

В исследованиях с участием здоровых добровольцев с сухой кожей были показаны увлажняющие свойства стимулятора репарации тканей декспантенола. Была выявлена способность декспантенола улучшать гидратацию рогового слоя и уменьшать трансэпидермальную потерю воды [19-21]. У декспантенола обнаружена также способность защищать кожу от воздействия раздражителей $[22,23]$. Обработка раздражителем лаурилсульфатом натрия участков кожи, на которую в течение 21 дня наносили декспантенол, не привела к повышению трансэпидермальной потери воды, что свидетельствует о сохранении защитного барьера кожи на фроне применения декспантенола [19]. Было также показано, что декспантенол стимулирует эпителизацию и обладает противозудным и противовоспалительным эфффектом при индуцированной ультрафриолетом эритеме [24].

Стимулятор репарации тканей декспантенол является активным ингредиентом препарата Бепантен, который выпускается в фрорме крема и мази. Содержание декспантенола в мази и креме Бепантен составляет $5 \%$.

После топической аппликации декспантенол легко проникает в кожу, где быстро метаболизируется с образованием пантотеновой кислоты (витамин В5), которая является компонентом коэнзима А (CоA). Коэнзим А действует как белок - переносчик ацильных групп и, будучи компонентом цикла Кребса, является важным участником клеточного метаболизма [25]. Метаболические процессы, в которых участвует коэнзим А, в конечном счете приводят к регенерации эпителия [26].

Способность декспантенола стимулировать процессы регенерации кожи позволяет использовать препараты, его содержащие, для ухода за кожей и наружной терапии различных заболеваний кожи [27]. В многоцентровом исследовании с участием 483 больных атопическим дерматитом, ихтиозом, псориазом и контактным дерматитом, которым требовался уход за кожей, назначали аппликации декспантенола. Было отмечено значительное уменьшение проявлений раздражения кожи: ксероза, эритемы и зуда [28]. Было обнаружено, что эффективность декспантенола в топической терапии легкой тяжести и среднетяжелого атопического дерматита у детей сопоставима с эффективностью гидрокортизона [29].

Предпочтительной лекарственной формой декспантенола для использования у больных атопическим дерматитом является крем. При обострениях заболевания крем декспантенол (Бепантен) может использоваться в комбинации с топическим глюкокортикостероидом МПА (Адвантан), который наносят на очаги поражения кожи утром, а вечером проводятся аппликации крема Бепантен. В период ремиссии атопического дерматита крем Бепантен может использоваться для ухода за сухой кожей больных.

\section{Заключение}

Основные задачи топической терапии больных атопическим дерматитом - восстановление защитного липидного барьера эпидермиса, подавление воспалительной реакции в коже и устранение зуда - могут быть решены использованием комбинации топического глюкокортикостероидного препарата Адвантан, в состав которого входит 0,1\% МПА, и крема Бепантен, содержащего в качестве активного ингредиента 5\% декспантенол. Достоинствами топического глюкокортикостероидного препарата Адвантан являются наличие препарата в 4 лекарственных формах (эмульсия, крем, мазь и жирная мазь), что позволяет выбирать лекарственную форму Адвантана с учетом стадии и локализации поражения кожи, быстрое развитие терапевтического эффректа, возможность использования препарата у детей, начиная с 4-месячного возраста, незначительное количество нежелательных явлений, связанных с применением препарата. Эффрективность препарата Адвантан в лечении больных атопическим дерматитом может быть повышена использованием крема Бепантен, способствующего увлажнению кожи. I

\section{Литература}

1. Schmid-Grendelmeier P., Simon D., Simon P. et al. Epidemiology, clinical features, and immunology of the "intrinsic" (non-lgE mediated) type of atopic dermatitis (constitutional dermatitis). Allergy 2001; 56: 841-849.

2. Wüthrich B., Schmid-Grendelmeier P. The atopic eczema/dermatitis syndrome. Epidemiology, natural course, and immunology of the "IgE-associated ("extrinsic") and the nonallergic ("intrinsic") AEDS. J Investig Allergol Clin Immunol 2003; 13: 1 - 5 .
3. Wüthrich B., Cozzio A., Roll A. et al. Atopic eczema: genetics or environment? Ann Agric Environ Med 2007; 14: 195-201.

4. Metz M., Wahn U., Gieler U. et al. Chronic pruritus associated with dermatologic disease in infancy and childhood: Update from an interdisciplinary group of dermatologists and pediatricians. Pediatr Allergy Immunol 2013: 24: 527-539.
5. Slattery M.A., Essex M.J., Paletz E.M. et al. Depression, anxiety and dermatological quality of life in adoloscents with atopic dermatitis. J Allergy Clin Immunol 2011; 128 (3): 668-671.

6. Dalgard F., Lien L., Dalen I. Itch in the community: associations with psychosocial factors among adults. J Eur Acad Dermatol Venerol 2007; 21 (9): 215-219 
7. Weisshaar E., Diepgen T.L., Bruckner T. et al. Itch intensity evaluated in the German Atopic Dermatitis Intervention Study (GADIS): correlations with quality of life, coping behavior and SCORAD severity in 823 children. Acta Derm Venereol 2008; 88 (3): 234-239.

8. Eichenfield L.F., Tom W.L., Berger T.G. et al. Guidelines of care for the management of atopic dermatitis: section 2. Management and treatment of atopic dermatitis with topical therapies. J Am Acad Dermatol 2014; 71 (91): 116_-132.

9. Adaskevich V.P., Baltabaev M.K.. Korsunskaya I.M. i soavt. Konsensus dermatologov stran SNG po dermatitam i ekzeme. Consilium Medicum. Dermatologiya. 2014: Ekstravypusk, 18 S. [Адаскевич В.П., Балтабаев М.К., Корсунская И.М. и соавт. Консенсус дерматологов стран СНГ по дерматитам и экземе. Consilium Medicum. Дерматология. 2014: Экстравыпуск, 18 с.]

10. Haneke $E$. The treatment of atopic dermatitis with methylprednisolone aceponate (MPA), a new topical corticosteroid. J Dermatol Treatm 1992; 3 (Suppl.2): 13-15.

11. Garcia Ponte L., Ebert U. Frontiers of rapid itch relief: a review of methylprednisolone aceponate. 2012; 26 (Suppl.6): 9-13.

12. Luger T.A. Balancing efficacy and safety in the management of atopic dermatitis: the role of methylprednisolone aceponate. J Eur Acad Dermatol Venereol 2011; 25: 251-258.

13. Bieber T., Vick K., Fölster-Holst R. et al. Efficacy and safety of methylprednisolone aceponate ointment $0.1 \%$ compared to tacrolimus $0.03 \%$ in children and adolescents with an acute flare of severe atopic dermatitis. Allergy 2007; 62 (2): 184-189.
14. Günther C., Kecskes A., Staks T., Täuber U. Percutaneous absorption of methylprednisolone aceponate following topical application of $\mathrm{Ad}$ vantan ${ }^{\circledR}$ Iotion on intact, inflamed and stripped skin of male volunteers. Skin Pharmacol Appl Skin Physiol 1998; 11: 35—42.

15. Ruzicka T. Methylprednisolone aceponate* in eczema and other inflammatory skin disorders - a clinical update. Int J Clin Pract 2006; 60 (1): 85-92.

16. Hoffmann K., Auer T., Stücker M. et al. Comparison of skin atrophy and vasoconstriction due to mometasone furoate, methylprednisolone and hydrocortisone. J Eur Acad Dermatol Venereol 1998; 10: 137-142.

17. Akdis C.A., Akdis M., Bieber T. et al. Diagnosis and treatment of atopic dermatitis in children and adults: European Academy of Allergology and Clinical Immunology / American Academy of Allergy, Asthma and Immunology / PRACTALL Consensus Report. Allergy 2006; 61: 969—987.

18. Szczepanowska J., Reich A., Szepietowski J.C. Emollients improve treatment results with topical corticosteroids in childhood atopic dermatitis: a randomized comparative study. Pediatr Allergy Immunol 2008; 19: 614—618.

19. Goujon C., Alleaume B., De Bony R., Girard P. Randomised single-blind pilot comparison study of the efficacy and tolerability of Bepanthen ointment in subjects with bilateral dryness of the hands. Realitees Therapeutiques en DermatoVenerologie 1997; 66: 47-33.

20. Gehring W., Gloor M. Effect of topically applied dexpanthenol on epidermal barrier function and stratum corneum hydration. Results of human in vivo study. Arzneimittelforsch 2000; 50 : $659-663$.
21. Camargo F.B. Jr., Gaspar L.R., Maia Campos P.M. Skin moisturizing effects of panthenol-based formulations. J Cosmet Sci 2011; 62: 361—370.

22. Proksch E., Nissen H.P. Dexpanthenol enhances skin barrier repair and redusec inflammation after sodiom lauryl sulphate-induced irritation. J Dermatolog Treat 2002; 13: 173-178.

23. Biro K., Thaci I.D., Ochsendorf F.R. et al. Efficacy of dexpanthenol in skin protection against irritation: a double-blind, placebo-controlled study. Contact Dermatitis 2003; 49: 80—84.

24. Ebner F., Heller A., Rippke F., Tausch I. Topical use of dexpanthenol in skin disorders. Am J Clin Dermatol 2002; 3: 427-433.

25. Wiederholt T., Heise R., Skazik C. et al. Calcium pantothenate modulates gene expression in proliferating human dermal fibroblast. Exp Dermatol 2009; 18: 969-978.

26. Girard P., Beraud A., Goujon C. et al. Effect of Bepanthen ointment on the graft-donor site wound-healing model: double-blind biometrological and clinical study, with assessment by the patient, versus the vehicle. Nouv Dermatol 1998; 17: 559-570.

27. Heise R., Scazik C., Marquardt Y. et al. Dexpanthenol modulates gene expression in skin wound healing in vivo. Skin Pharmacol Physiol 2012; 25: 241-248.

28. Bahmer F., Pigatto P., Wehmeyer A. Adjuvante Hautpflege mit den dexpanthenolhaltigen Formen von pH5-Eucerin. Dtsch Derm 1997; 45 (4): 366-373.

29. Udompataikul M., Limpa-O-Vart D. Comparative trial of $5 \%$ dexpanthenol in water-in-oil formulation with $1 \%$ hydrocortisone ointment in the treatment of childhood atopic dermatitis: a pilot study. J Drugs Dermatol 2012; 11: 366—374.

об авторе:

В.В. Чикин - к.м.Н., старший научный сотрудник отдела дерматологии ФГБУ «ГНЦДК» Минздрава России, Москва

Конфликт интересов

Автор заявляет об отсутствии потенциального конфлликта интересов, требующего раскрытия в данной статье 